\title{
TURISMO NEW AGE: EXPLORACIÓN TEÓRICO-EMPÍRICA DE UN CONCEPTO EN DISCUSIÓN.
}

\author{
María José Grego \\ Licenciada en Ciencia Política Universidad Católica de Temuco. \\ Magister (C) Turismo UACh \\ Cientista Político Universidad Católica de Temuco \\ Francisco Vega Duarte \\ Mg. Gobierno y Sociedad U. Alberto Hurtado \\ Licenciado Ciencia Política PUC \\ Doctorante Ciencias Sociales UFRO \\ Académico UC Temuco. Departamento de Sociología y Ciencia Política
}

\section{Resumen}

Se explora como se ha caracterizado un tipo particular de turismo, que desarrolla servicios y productos en los destinos turísticos, de experiencias en base a la espiritualidad y religiosidad new age. Se entiende por turismo new age, un conjunto de servicios y productos de destinos turísticos basados en la generación de experiencias y consumos vinculados a la espiritualidad universal, que enfatiza la importancia de pueblos originarios, formas de espiritualidad oriental, interacción con la naturaleza, que se integran en prácticas de sanación y búsqueda trascendental. Se revisa la literatura especializada sobre new age, turismo, turismo new age, así como sus implicancias en el desarrollo de destinos turísticos, que permitan exploraciones sobre los efectos territoriales y culturales. Se propone una aproximación para el caso de Pucón, lugar donde se condensa el turismo en Norpatagonia. El turismo new age es desarrollado por un tipo de grupo de turista de elite, los cuales complejizan los diseños de experiencias en base a las implicancias en el territorio donde se emplazan los destinos turísticos, así como las prácticas sociales y culturales de las comunidades receptoras.

Palabras clave: turismo new age, destinos turísticos, condiciones para experiencias, calidad y sustentabilidad. 


\title{
TOURISM NEW AGE: THEORETICAL-EMPIRICAL EXPLORATION OF A CONCEPT IN DISCUSSION.
}

\author{
María José Grego \\ Licenciada en Ciencia Política Universidad Católica de Temuco. \\ Magister (C) Turismo UACh \\ Cientista Político Universidad Católica de Temuco \\ Francisco Vega Duarte \\ Mg. Gobierno y Sociedad U. Alberto Hurtado \\ Licenciado Ciencia Política PUC \\ Doctorante Ciencias Sociales UFRO \\ Académico UC Temuco. Departamento de Sociología y Ciencia Política
}

\begin{abstract}
It explores how it has characterized a particular type of tourism, which develops services and products in tourist destinations, experiences based on spirituality and new age religiosity. New age tourism is understood as a set of services and products of tourist destinations based on the generation of experiences and consumptions linked to universal spirituality, which emphasizes the importance of native peoples, forms of oriental spirituality, interaction with nature, Integrate in practices of healing and transcendental pursuit. We review the specialized literature on new age, tourism, new age tourism, as well as its implications in the development of tourist destinations, allowing explorations on territorial and cultural effects. An approximation is proposed for the case of Pucón, place where the tourism in Norpatagonia is condensed. The new age tourism is developed by a type of elite tourist group, which complex the designs of experiences based on the implications in the territory where the tourist destinations are located, as well as the social and cultural practices of the receiving communities
\end{abstract}

Keywords: new age tourism, tourism destinations, conditions for experiences, quality and sustainability. 


\section{Introducción}

El presente artículo nace como una forma de aportar a la reflexión sobre el turismo en Chile, particularmente un tipo de turismo basado en los valores, prácticas y costumbres vinculados al movimiento New Age. Se explora como se ha caracterizado un tipo particular de turismo, basado en el desarrollo de servicios y productos en los destinos turísticos, de experiencias en base a la espiritualidad y religiosidad de una cierta espiritualidad universal, que enfatizan lo étnico, lo oriental (orientalismo, en clase de Edward Said), lo natural y la sanación/experiencia, como ejes de este tipo de turismo.

Para ello, se elaboran observaciones generales sobre turismo, new age, turismo y cultura, para luego revisar lo pertinente para el turismo new age (TNA). Esto implica identificar prácticas sociales y sus implicancias en el desarrollo de destinos turísticos, así como explorar implicancias de investigaciones sobre turismo new age en Norpatagonia, particularmente en Pucón. Estas implicancias se observan en los planos territoriales y culturales.

El turismo es un tipo de experiencia moderna, ya que las acciones y hechos que se generan son observables en una cantidad heterogéneas de servicios y proveedores en los diferentes destinos turísticos. Hoy en día, la experiencia turística ha dado pie a un turismo centrado en las búsquedas espirituales y religiosas, siendo un tipo particular de este tipo de turismo, el que ha configurado la espiritualidad universal o new age. Este tipo de turismo es un modo adaptativo que permite complejizar la experiencia turística, en virtud de las exigencias de una elite turística que busca sanación, expansión, nuevas sensaciones.

Se pretende responder las siguientes preguntas: ¿Cuáles son las definiciones sobre que comprenden este tipo de turismo? ¿Qué implicancias tiene para el desarrollo de destinos turísticos? ¿Qué se puede reflexionar para el caso Pucón, punto central en el desarrollo

del turismo en Norpatagonia, lugar de alta proliferación de turismo new age? El turismo new age al relevar como importante a las comunidades indígenas, el orientalismo, la interacción con la naturaleza y las formas de medicina alternativa, permite un crecimiento de servicios y productos en Pucón, en el entendido que es un lugar de condensación del turismo new age en Sudamérica. Ello implica que los destinos deben adaptarse a un tipo de grupo de turista de elite, mayor complejización los diseños de experiencias en base a las implicancias en el territorio y cultura donde se emplazan los destinos turísticos.

"Desde su génesis el turismo fue una actividad elitista y aristocrática hasta bien entrado el siglo XX. Su masificación, o extensión a otras clases sociales, emerge con el descanso 
programado (Callizo 1991), específicamente con la entrada en vigencia del derecho a vacaciones pagadas suscrito a la Convención $\mathrm{n}^{0} 52$ de la Organización Internacional del Trabajo en 1936. De esta manera, su consolidación como fenómeno, ahora también de las masas populares, es el resultado de sus conquistas laborales (Santana 1997; López 2002). Sin embargo, su despegue como actividad de masas será progresivo hasta llegada la década de 1950 (Boyer 2002; Gordon 2002)" (Espinosa, 2014, pág. 14).

Siguiendo a de la Torre y Gutiérrez (2011), new age es "el advenimiento de una nueva era astrológica en la que la tierra vivirá bajo la influencia de la constelación de Acuario y que, en oposición a la precedente Era de Piscis, estará marcada por la convivencia armónica entre todas las tradiciones culturales existentes entre sí y con la naturaleza; el universo como un sistema energético en el que cada elemento se encuentra interconectado, por lo que el individuo adquiere una nueva responsabilidad de dimensiones cósmicas sobre su propio manejo energético. La transformación personal basada en el autoconocimiento y la sanación que ofrecen las distintas tradiciones, es una "dulce conspiración" (Ferguson, 1981), un medio de transformación social y cultural profunda (Gutiérrez Zúñiga, 1996; Carozzi, 1999) (de la Torre, R y C. Gutiérrez, 2011, pág. 188).

\section{Observaciones teóricas generales}

Como forma de generar una revisión coherente sobre los aspectos teóricos sobre el turismo new age, es que a continuación se ha organizado la información en función de criterios sobre el turismo, para luego indicar ideas sobre lo que se ha denominado como new age. Esto tiene como sentido, indicar que previo a identificar criterios sobre el turismo new age, se requiere indicar observaciones generales sobre turismo y new age. En el punto se ahondará sobre los aspectos sociales y culturales que dan forma a turismo new age, así como a los destinos turísticos que afectan.

"El turismo es un fenómeno de relevancia social y económica que evolucionó a lo largo de los siglos XIX y XX para asentarse en prácticamente todos los rincones del mundo. Entre los factores que explican su crecimiento están el desarrollo y acceso de nuevas tecnologías de comunicación y transporte, su habitual presentación como alternativa económica de bajos impactos socioambientales, la comunicación de escasez patrimonial y la consolidación de economías locales vinculadas a la industria del ocio" (Santana 1997; Callizo 1991) (Espinosa, 2014, pág. 9).

"El turismo es una actividad fundada en la comercialización de la hospitalidad, concibiéndolo como un fenómeno complejo con funciones claramente definidas: "es un proceso cíclico cuya función es la dislocación identitaria y desplazamiento físico a un espacio ajeno al lugar de residencia o habitual con fines recreativos para una posterior 
reinserción cumpliendo temporalmente las necesidades psíquicas de evasión, curiosidad y extraordinariedad propia de cualquier forma de ocio" (Espinoza, 2014, pág. 19).

Esto hace que las culturas y sus espacios sean resignificados por efectos del cambio en el tiempo para el ocio, "el viaje de ocio es la base conceptual del turismo" (Espinoza, 2014, pág. 16). Esta base conceptual da cuenta de un fenómeno, el cual permite gatillar efectos en los diferentes sistemas funcionales. "El fenómeno turístico es el que semanifiesta en los distintos

sistemas funcionales de la sociedad (el económico, político, educativo y el del derecho como ejemplos claros), generando un efecto en cada sistema en el que introduce una irritación; cuya dimensión puede ser capaz de producir un cambio de su estado anterior y hasta un acoplamiento en la estructura de las operaciones de los sistemas" (Osorio 2000, pág. 232).

En cuanto a lo que se puede entender por new age, siguiendo a de la Torre y Gutiérrez (2005), "la definición de New Age es tema de controversia, debido a que no sólo se ha usado para designar a un movimiento religioso específico, aunque de límites ambiguos por su carencia de definición en cuanto a liderazgo y doctrina, así como por constituirse como una red de movimientos y no como una institución - sino también para nombrar a una forma laxa de consumo religioso individual e itinerante entre diversas tradiciones espirituales propias de la modernidad (de la Torre \& Gutiérrez, 2005 pag. 57).

Ante la necesidad de entender en que consiste el new age, Lombardi (2011), señala, "el fenómeno New Age se manifiesta a través de diferentes formas que son constituidas desde el esoterismo, el relativismo, de los símbolos religiosos, de las filosofías orientales con una "ofrenda espiritual" que permite a los adeptos de optar entre múltiples universos de significaciones para buscar el que puede ofrecer un sentido a la existencia" (Lombardi, 2011 pág. 2). Ese sentido de la existencia se vincula a una concepción de sanación. "Se desconoce hasta qué punto esta concepción de sanación se forjó en la gama de movimientos que se cobijan en la New Age, pues según la definición que de ella proporciona Cristina Gutiérrez se trata de "una red de movimientos espirituales conformados por pequeños grupos autónomos carentes de un liderazgo único, pero con una orientación común: la búsqueda de la transformación individual para colaborar en el advenimiento de una nueva utopía de proporciones cósmicas" (Gutiérrez, 1996: 11) (Hernández, 2005, pág. 22). “A pesar de recurrir a una racionalidad de superación individualista y utilizar conceptos ultramodernos como "empoderamiento" o "sinergias", o expresiones en inglés como "coach" "yoga village" o "mindfulness", en estos medios se evoca constantemente el origen indígena de la supuesta sabiduría impartida (la cuestión de la identificación como indígena-tradicional es clave)” (Sarrazín, 2015, pág.175). 
Articular una aproximación al turismo como fenómeno cultural, nos lleva a preguntarnos sobre las condiciones sociales, sean estas colectivas o individuales, debido a que el turismo irrita los rasgos identitarios de los lugares, en tanto lo único como destino turístico. "Igualdad y diferencia son conceptos que están íntima y lógicamente relacionados: lo que hace que un individuo sea similar a otros, le distingue de los que no son esos; por lo tanto, una de las características que tenemos en común con el grupo de iguales es lo que nos diferencia de los demás grupos. Así pues, cuando se habla de la identidad de un sujeto o de un grupo se hacen presentes estas relaciones de igualdad y diferencia (Labrado, 2008, pág. 96). Lo relevante, como señala Sarrazín (2015), es que estas entidades sociales están bombardeadas por imágenes globalizadas, como canal por tanto del surgimiento de una cultura turística new age. "Las imágenes que se presentan en la publicidad turística, especialmente en los productos de turismo cultural, presentan los rasgos identitarios de los lugares, aquello que deja constancia de su historia dirigiendo la mirada del turista hacia aquello que es único y que no puede ser encontrado en otro lugar, como una distinción entre los pueblos" (de los Monterios et al, 2012, pág. 1414). "La mayor parte de las representaciones sobre el chamanismo no proceden de lo que los indígenas dicen, sino de toda la información globalizada que consumen los indigenistas" (Sarrazín, 2015, pág. 173).

Uno de los ejes de la emergencia de lo new age ha sido una vuelta de la mirada a los indígenas. "El reconocimiento, el respeto y la preservación de las tradiciones étnicas se convirtieron en valores importantes, sobre todo en los sectores altamente educados de la población urbana, tendencia que formaba parte de la globalización de los recursos discursivos racistas y un cierto elogio de la diferencia cultural en los países del Norte. Al mismo tiempo, el antropólogo y otros científicos sociales desempeñaron un papel importante al inspirar y dar visibilidad a esos movimientos de minorías basados en la identidad racial y cultural "(Sarrazín, 2009) (traducción propia).

Se entenderá en el siguiente artículo como turismo new age, a un conjunto de servicios y productos de destinos turísticos basados en la generación de experiencias y consumos vinculados a la espiritualidad universal, que enfatiza la importancia de pueblos originarios, formas de espiritualidad oriental, interacción con la naturaleza, que se integran en prácticas de sanación y búsqueda trascendental. Esto implica entre otras cosas, como señala de la Torre et al. (2005) "mercado espiritual (spiritual marketplace) en el que los bienes o mercancías que circulan en los contextos de las religiones tradicionales y en del movimiento Nueva Era pueden contener un significado sagrado, y no hay objeción a la comercialización o creación de bienes religiosos (Zaidman, 2003 pág. 346) (de la Torre \& Gutiérrez, 2005 pág.56). "Los grupos que el turismo atiende no son simplemente colecciones de individuos que se someten pasivamente a un mismo producto turístico, sino grupos de interés, que demandan productos y actitudes especializadas de atención hacia sus objetivos compartidos" (Hiernaux-Nicolas, 2000, pág. 22). 
Según Argyriadis (2005), "el desarrollo del turismo es regularmente señalado como un elemento determinante en la llamada comercialización de la religión" (Argyriadis, 2005, pág. 31). Es en esta paradoja, donde se da cuenta de otra paradoja, en cuanto a que "todos estos discursos y práctica relacionados con la valoración positiva de las culturas indígenas van acompañados de críticas explícitas contra "nuestra cultura", "Occidente", "la modernidad" o su "Progreso", el cual estaría destruyendo los saberes ancestrales, así como destruye los recursos naturales y no presenta formas de "vida sana". Se trata, como se ha observado en otros países del mundo, de la búsqueda de una "alteridad espiritual" (Benveniste, Hernandez y Selim 2004; Pons 2004) que contrarreste las tendencias supuestamente demasiado "destructoras", "materialistas" o "deshumanizantes" de la cultura moderna. El indigenismo local, en efecto, utiliza un buen número de ese tipo de ideas, las cuales estaban ya presentes en movimientos nacidos en el Norte global como la "contra-cultura" y el "New Age" (Sarrazín, 2015, pág. 177).

El turismo new age como una práctica social, complejiza y especializa. Es una amalgama, en tanto genera acoples irritando, que para el caso del turismo new age, irrita comunidades y territorios en base a la generación de servicios y productos turísticos en base ala espiritualidad y religiosidad de trascendentalidad universal. "Las estructuras de cada sistema seleccionan solo aquellos elementos del turismo que son autorreferentes, discriminando las posibles relaciones entre los elementos y el tiempo específico con el que se suceden, construyendo históricamente la evolución" (Osorio 2000, pág. 232). El turismo y su relación con el new age plantea una síntesis particular derivado de su carácter híbrido y de grupos de turistas "tribales". "El hibridismo con matriz new age es un referente de las identidades indígenas imaginadas, y está produciendo sus propias versiones esencializadoras de los rituales valorados como indios o prehispánicos (de la Torre, R y C. Gutiérrez, 2011, pág. 185). Así mismo, "estos fenómenos de "tribalización" son importantes para el desarrollo del turismo, tienen implicaciones directas en él (Hiernaux-Nicolas, 2000, pág 22).

En cuanto a los destinos turísticos y el turismo new age, se puede señalar que "en su sentido más amplio, la conformación de un destino turístico es el resultado de procesos que incluyen la construcción de una imagen sobre las condiciones sociales, políticas, económicas y culturales de un lugar, así como la creación de una red de proveedores de bienes y servicios, de un tejido institucional y de las estructuras que vigilan el cumplimiento de la ley y la interacción respetuosa de todos los involucrados en la existencia, permanencia y cambio del sitio en cuestión. (Bringas \& Verduzco, 2008:XX). Esto implica que la búsqueda de la sanación, como uno de los puntos de la práctica de experiencias turísticas new age. "La sanación espiritual, en esta dimensión sugerida de "sistema experto", se objetiva de diversas maneras: como capacitación técnica ofertada en cursos, manuales, demostraciones; como servicio terapéutico (masajes, sesiones); como instrumental de apoyo (cristales, fragancias, agujas, 
mesas para masaje) y ambientación de entornos (inciensos, adornos, grabaciones musicales); y el incentivo sostenido de mejorar mientras más técnicas de sanación se conozcan” (Hernández, 2005, pág. 23).

Luego de detallar esta serie de antecedentes teóricos en el desarrollo de una definición sobre el turismo new age, es que se propone identificar a continuación una aproximación empírica en un espacio determinado, que pueda responder a las condiciones de destino turístico new age. Para ello se propone observar un lugar particular de Norpatagonia, puntualmente en la zona andina, que ha sido a lo largo de la historia del turismo global un punto relevante de atracción turística, como es el caso de Pucón. La adopción del lugar no es simplemente por arbitrariedad casuística, sino por una serie de características que hoy tiene el sistema de turismo de Pucón, que en su complejización ha adquirido una sofisticación en materia de servicios y productos turísticos de turismonew age.

\section{¿Por qué Pucón?}

Se considera atractivo proponer un lugar como Pucón, ya que hoy en día es posible identificar una serie de servicios y productos de turismo new age, vinculado a experiencias y sanaciones vinculadas a las condiciones étnicos de la zona, así como a las oportunidades que ofrece la geografía (termas) y naturaleza, y la constante instalaciones de desde fines del siglo XX de proveedores de servicios y productos vinculadas a la espiritualidad universal, así como a prácticas y cultos orientales.

Como señala Booth y Lavín (2013), las condiciones del destino turístico de Pucón se comienzan a desarrollar a mediados del siglo XX, derivado de las acciones de Ferrocarriles del Estado de Chile. A esto se complementa lo desarrollado por el Estado chileno, similar a lo realizado por el Estado Argentino, de potenciar el desarrollo de Parques Nacionales, desde inicios del siglo XX. Ya finalizado el siglo XX es posible identificar un destino marcado por una alta complejización y especialización del turismo en la

zona, siendo un caso de turismo de escala mundial en Chile y en Norpatagonia Andina. "Las infraestructuras instaladas en el sur a partir de la ocupación chilena de este espacio normaron las relaciones entre las personas y el territorio. En este contexto, la construcción de la vía férrea adquiere valor para la interpretación histórica no sólo debido a sus resultados materiales -que facilitaron el acceso a la Araucanía y la región lacustre y contribuyeron a integrar el territorio ocupado por el estado nacional-; también incidió en el ámbito de lo simbólico, especialmente debido a la influencia que la Empresa de los Ferrocarriles del Estado tuvo en la normalización de las ideas sobre el paisaje del sur durante el siglo xx" (Booth \& Lavín 2013 pág. 57). 
Ejemplo de ello, como se ha estado investigando por los autores, es la proliferación de manera irregular de proveedores de turismo new age. Ejemplo de ello es Cóndor Blanco y su líder Suryavan Solar, Kitralma, el Templo Budista Champaling, entre otros. Aesto se suma la oferta de servicios y productos asociados a la oferta de termas y hoteles, así como de servicios de alimentación vegana, vegetariana, vinculada tanto al naturalismo heredero del hipismo, así como a la práctica de yoga, experiencias místicas y del senderismo vinculado a Rod Walker. Interesante es la situación de las comunidades mapuches como proveedores de experiencias de turismo new age. Si bien los mapuches fueron comunidades que el Estado erradicó, redujo y chilenizó, con el correr del tiempo, producto tanto de la emergencia de lo étnico a nivel global como residuo de la globalización, y de las políticas que nacen con el pacto de Nueva Imperial suscrito por Patricio Aylwin en 1989, el Estado Chileno, a punta de instrumentos y programas de políticas públicas, los insertó como proveedores de turismo.

Ello ha implicado la generación de valor reputacional y público de los emprendimientos mapuches, estando inserto en las cadenas formales de turismo local, así como en el diseño de redes propias de asociatividad. Ejemplo interesante de ello es lo realizado entorno al Festival de Puesco Fest, instancia donde se condensa en unos días al año, una especie

de encuentro new age, que incluye música, comida, experiencias, amor a los ríos, entre otros, todo organizado entre la comunidad mapuche del sector y el resto de la comunidad organizada en red. Otras experiencias más tradicionales son las ofertadas por organizaciones mapuches tanto rurales como urbanos, es el emprendimiento de la venta de experiencias de vivir en rucas, reconocer espacios y paisajes con carga identitaria, así como la búsqueda de sanación en base a la medicina tradicional indígena.

\section{Implicancias del turismo new age en Norpatagonia}

En el transcurso del artículo se ha pretendido en primer término esbozar una descripción teórica sobre un posible espacio particular de turismo. Ello implica ir respondiendo la primera pregunta propuesta en la introducción. Queda por ello explorar respuestas sobre las implicancias en los destinos turísticos de este tipo de turismo, así como exponer una serie de observaciones sobre Pucón, como lugar que condensa el turismo new age en Norpatagonia. Se reitera que los autores del presente artículo, están desarrollando una investigación sobre el turismo new age, y que en las preliminares descripciones de resultados, se constata la proliferación de proveedores de turismo, con experiencias centradas en lo étnico, lo oriental, lo natural y la sanación. El turismo new age al relevar como importante a las comunidades indígenas, el orientalismo, la interacción con la naturaleza y las formas de medicina alternativa, permite un crecimiento de servicios y productos, complejizando y especializando la oferta. 
Como señala la literatura, "el turismo, como modelo de desarrollo territorial, genera diversas trayectorias sociales y económicas que han sido descritas y clasificadas por autores especializados. Estos observan y caracterizan el comportamiento de los modelos de desarrollo turístico asociando su trayectoria a factores sociales, económicos y administrativos que se orientan a probabilizar la visita turística. Gormsen (1981, en

Callizo 1991: 100) aplica un modelo espacio-temporal dividido en una serie de etapas para describir la emergencia de zonas con vocación turística, las que comienzan con los albores del turismo asociada a las urbes industrializadas de Inglaterra, pasando por su sostenido crecimiento en la segunda mitad del siglo XX hasta llegar a su mundialización, que comienza a forjarse a partir de la década de 1980. Por su parte, para Pearce (1986, en Santana 1997: 34) los modelos de desarrollo turístico se pueden agrupar en dos: el modelo integrado, caracterizado por estar cerrado en torno a un solo promotor turístico que excluye al resto de la población, y el modelo catalítico, que se caracteriza por estar abierto a la participación de la población local. Peck y Lepie (1977, en Callizo 1991: 103) ofrecen una tipología basada en el crecimiento turístico, el que pudiendo ser rápido, lento o transitorio les permite caracterizar los consecuentes impactos en la población residente (Espinosa, 2014, pág. 27).

Al asumir Pucón, en el entendido que es un lugar de condensación del turismo new age en Sudamérica, implica un destino que se ha adaptado al tipo de grupo de turista de elite, valorizando con ello el territorio y cultura donde se emplaza como destino turístico. "Por ello es que ciertas formas de turismo que se han acercado a estos "grupos tribales" han logrado un éxito notorio en virtud de que su oferta coincide con ciertas demandas muy particulares. Este es el caso de la atención de grupos de la tercera edad, de grupos ambientalistas, vegetarianos, veganos o defensores del New Age, por citar algunos ejemplos" (Hiernaux-Nicolas, 2000, pág 22).

En cuanto a lo territorial, "aunque la operación de selección de los temas, fotografías, escenas, personajes y actividades que construyen la realidad del destino es una operación propia del sistema de los mass media, estos responden a estímulos provenientes principalmente de los sistemas político y económico puesto que la comunicación turística en los medios de comunicación es heterorreferente a las políticas públicas y a las estrategias económicas tendientes a impulsar o consolidar el desarrollo de las regiones ya que en el imaginario del turismo se le percibe a éste como

un factor de crecimiento económico (de los Monteros, 2012, pág. 1425). Como señala el Pladeco (Plan de desarrollo comunal) 2016 - 2020 de Pucón, "el turismo, es un sector económico que desempeña un rol de gran importancia en el desarrollo económico de los territorios, pues por una parte atrae inversión nacional y extranjera orientada a las actividades turísticas e impulsa la creación y el mejoramiento 
de la infraestructura disponible mediante la construcción de aeropuertos, autopistas, puertos y urbanización, en general, y por otra parte contribuye a impulsar el desarrollo de las diferentes actividades que son demandadas por los turistas tales como la alimentación, agencias de viajes, transportes de pasajeros, centros de diversión, compras de artesanías, otros productos y servicios de alojamiento (Pladeco, 2016, pág. 57).

En el plano cultural, siguiendo a Sarrazín (2015), se puede señalar que, "contrariamente a lo que se suele pensar, las similitudes en los discursos sobre lo étnico que se observan en países como Colombia, Chile, Francia, Islandia, Holanda o Estados Unidos, no se deben a supuestas similitudes culturales entre los grupos étnicos representados (sean de Suramérica, Norteamérica o la India), sino a algunas características socioculturales comunes a los sujetos que -aunque no se conozcan y vivan a miles de kilómetros de distanciacomparten cierto tipo de imaginarios positivos sobre lo étnico" (Sarrazín, 2015, pág. 166).

Interesante es lo que a continuación señala Sarrazín, para el caso de Pucón. "De manera análoga, podemos citar también el caso de una organización dirigida por un chamáncoach de origen chileno, la cual, a través de su oficina temporal en Bogotá, ofrece (a precios no abordables por las clases populares) talleres y conferencias. Se trata de una "organización internacional de desarrollo humano y superación personal" cuya misión es "reunir prácticas y filosofías ancestrales con las mejores técnicas de vanguardia del mundo moderno para el desarrollo integral del ser humano". Los clientes de esta organización son profesionales modernos (que también corresponden con la categorización sociológica que hemos hecho del indigenista) en busca de "saberes ancestrales" para el enriquecimiento personal y para "[liberarse] de trabas y pensamientos limitantes en la búsqueda de su estado de excelencia" (Sarrazín, 2015, pág. 175).

Siguiendo a Zunino (2012), Pucón entre los tres tipos de turismo que ofrece, hay uno que se puede entender como paragua mayor al turismo new age. Se refiere al turismo de elite centrado en enclaves de recreación y ocio que ofrecen un estándar de servicios similar al encontrado en los centros turísticos más reconocidos a nivel mundial.

Cómo se señala en el Pladeco de Pucón 2016 - 2020, "los atractivos turísticos de la comuna se relacionan mucho con la naturaleza: lagos, volcanes, termas, bosques, buen clima en los meses de verano, etc. A ello se le suma la importante infraestructura turística creada a través de los años, que incluye una cantidad y variedad importante de alojamiento para los turistas, restaurantes, casinos de juegos, club de yates, centros de ski, senderos para caminatas, deportes acuáticos y otros deportes extremos, buena infraestructura de transporte y comunicaciones, sucursales bancarias, agencias de viaje, tiendas, supermercados, etc. O sea, es una oferta turística bastante completa para que las personas se sientan a gusto en la comuna (Pladeco, 2016 pág. 57). 
Visto lo desarrollado a lo largo del artículo, podemos señalar en general que el turismo posee una relevancia social, en tanto forma particular de viaje de ocio. Al ser el turismo new age un tipo particular de turismo, este asume la relevancia de la comercialización de la hospitalidad, además de la comercialización de la búsqueda del sentido de la existencia, así como de la religiosidad / espiritualidad.

Estas imágenes híbridas son posibles de observar en Pucón, a partir de la existencia de proveedores deserviciosy productosquesecentranelponerenvalorturístico, laancestralidad mapuche, la inserción en la naturaleza, los horizontes de sentido basado en conocimientos milenarios y la búsqueda de sanación holística como sentido de la experiencia de vida.

\section{Conclusiones}

Se caracterizó un tipo particular de turismo, que desarrolla servicios y productos en los destinos turísticos, en base a la generación de experiencias de espiritualidad y religiosidad new age, tipo particular de turismo de elite que complejiza y especializa una oferta de servicios basados en la comercialización o mercantilización de la experiencia de búsqueda del sentido de la existencia y de la espiritualidad/religiosidad.

Para el caso de Pucón, esto se puede observar a la luz del concepto de turistificación, el cual "se entiende como un proceso por el cual se transforma un bien histórico, cultural o natural en un producto valioso en el mercado turístico" (Zúñiga, 2014, pág. 155). Para el caso, una mercantilización de la naturaleza y transformación del medio rural, "como la otra cara de la gentrificación (Gotham, 2005), que así mismo, modifica patrones de la cultura mapuche, las experiencias en la naturaleza y terapias en base a la búsqueda de la sanación y el sentido de la vida.

Se propuso una definición de turismo new age, como un conjunto de servicios y productos de destinos turísticos basados en la generación de experiencias y consumos vinculados a la espiritualidad universal, que enfatiza la importancia de pueblos originarios, formas de espiritualidad oriental, interacción con la naturaleza, que se integran en prácticas de sanación y búsqueda trascendental. Como se puede constatar en la información diagnóstica el turismo sigue siendo la actividad más relevante de la comuna, el incremento sostenido de los diversos indicadores es reflejo de ello. Sin embargo, como se releva por la propia comunidad, los recursos naturales son el eje de ello pero su fragilidad, sobrecarga, protección son lo que debe orientar todas aquellas acciones a definir tanto los actores privados como los públicos (Pladeco, 2016, pág. 132). 
Pucón resulta ser un interesante lugar en la medida que condensa en un espacio, tanto la consolidación de un destino turístico. El turismo new age es desarrollado por un tipo de grupo de turista de elite, los cuales complejizan los diseños de experiencias en base a las implicancias en el territorio donde se emplazan los destinos turísticos, así como las prácticas sociales y culturales de las comunidades receptoras. "El new age, término de difícil definición, será considerado tanto como un circuito en el que las tradiciones locales/autóctonas se ofrecen como fragmentos descontextualizados de su origen a buscadores espirituales cosmopolitas, como una matriz de resignificación de las mismas basadas en algunas creencias comunes: (de la Torre, R y C. Gutiérrez, 2011, pág. 188).

A partir de lo revisado, quedan muchas preguntas para seguir explorando más sobre este tipo de turismo, ya que da cuenta la puesta en valor de atributos de destinos turísticos más sofisticados, por tanto, con mayor generación de formas de gobernanza territorial del turismo. Esto mismo, pone retos a las instituciones a fin de poder generar dinámicas de planificación de la oferta de servicios y productos turísticos new age. Esto es más relevante en destinos donde se superponen tipos de turismos, en espacios territoriales altamente frágiles, y con poblaciones que cada día demandan más participación en la decisión e implementación de acciones.

Pucón ofrece experiencias de turismo new age que son necesarias de sistematizar. No es menor que se amplíe la oferta con la reciente puesta en marcha de la ruta del padre Francisco Valdés, iniciativa transfronteriza que busca potenciar un tipo de turismo religioso/espiritual católico. Así mismo, no es menor la cantidad de emprendimientos de sanación y terapia en la zona lacustre, que articulados están conformando cooperación, complementariedad y trabajo colaborativo, insertos en las redes de turismo local, nacional y global. Como señala Sarrazín, hay un caso particular de turismo de estas características en Chile, Pucón específicamente. Es cosa de recorrer las zonas rurales de la zona de estudio.

\section{Referencias}

Argyriadis, K. (2005). El desarrollo del turismo religioso en La Habana y la acusación de mercantilismo. Desacatos, (18), 29-52.

Booth, R., \& Lavín, C. (2013). Un hotel para contener el sur. ARQ (Santiago), (83), 5661.

Cataño G. (2003). Robert K. Merton. Espacio Abierto. Asociación Venezolana de Sociología.

de la Torre R. y Gutiérrez C. (2011) La neomexicanidad y los circuitos new age. ¿Un hibridismo sin fronteras o múltiples estrategias de sintesis espiritual?. Archives de sciences sociales des religions. 153 (janvier-mars 2011). Prisons et religions en Europe | Religions amérindiennes et New Age 
de la Torre, R., \& Gutiérrez, C. (2005). La lógica del mercado y la lógica de la creencia en la creación de mercancías simbólicas. Desacatos, (18), 53-70. de los Monteros, G. N. E., Osorio García, M., Torres Nafarrate, J., \& Esquivel Solís, E. (2012). www. redalyc. org. Estudios y Perspectivas en Turismo, 21(6), 1409-1432. des indigènes en Colombie. E-Migrinter, 4, 100-106.

Espinosa Polanco, P. (2014). Segregación socio-espacial en una urbe turística: La construcción turística de la ciudad de Pucón.

Etzioni, A. E. (1968). Los cambios sociales: fuentes, tipos y consecuencias (No. 301.15/E85sE). FCE.

Fernández, J. L. (2009). Las migraciones internacionales, nuevas identidades, nuevas ciudadanías. Ciencias Psicológicas, 3(1), 93-100.

Hernández Madrid, M. J. (2005). Entre las emergencias espirituales en una época axial y la mercantilización contemporánea de los bienes de sanación. Desacatos, (18), $15-28$.

Hiernaux-Nicolas D. (2000). EL TURISMO EN UN "MUNDO DESBOCADO": CAMBIOS Y PERSPECTIVAS. Universidad Autónoma Metropolitana. Unidad Xochimilco, Ciudad de México.e-mail:lares1@ibm.net

Li, L. (2008). A review of entrepreneurship research published in the hospitality and tourism management journals. Tourism management, 29(5), 1013-1022.

Lombardi, D. (2011). Neo-chamanismo: el ritual transferido.

Osorio García, M. (2000). Nuevos Caminos para el Estudio del Turismo desde la Teoría de Sistemas. Convergencia. Revista de Ciencias Sociales, 7(23).

Quijano, A. (2000). Colonialidad del poder, eurocentrismo y América Latina.

Sarrazín Martínez, Jean Paul. (2015). The protection of cultural diversity: reflexions on its origins and implications. Justicia, (27), 99-117. Recuperado en 19 de marzo de 2016, de http://www.scielo.org.co/scielo.php?script=sci_arttext\&pid=S012474412015000100006\&lng=es\&tlng=en. 10.17081/just.3.27.322.

Sarrazin Z, J. P. (2014). Las hojas sabias en otra casa. Análisis de la traducción de la Constitución Política colombiana a la lengua indígena inga. Signo y Pensamiento, 33(65), 16-31. Recuperado en 19 de marzo de 2016, de http://www.scielo.org.co/scielo. php?script=sci_arttext\&pid=S0120-48232014000200002\&lng=es\&tlng=es. 10.11144/ Javeriana.SYP33-65.hsoc.

Sarrazin, J. P. (2008). La "espiritualización" de los discursos neoindigenistas en Colombia. Trace. Travaux et recherches dans les Amériques du Centre, (54), 77-91 Sarrazin, J. P. (2016). Estructura, antiestructura y sistema-mundo en una comunidad alternativa. El caso de los "jipi-koguis" en la Sierra Nevada de Santa Marta. Hallazgos, 13(25).

Sarrazín, J.P. (2009). Le role des élites intellectuelles dans le processus de visibilisation

Sarrazin, Jean Paul, \& Rincón, Lina. (2015). La conversión al islam como estrategia 
de cambio y diferenciación en la modernidad. Revista de Estudios Sociales, (51), 132-145. Recuperado en 19 de marzo de 2016, de http://www.scielo.org.co/scielo. php?script $=$ sci

arttext\&pid=S0123-885X2015000100011\&lng=es\&tlng=es. 10.7440/res51.2015.10.

Soto, H., \& Schuschny, A. R. (2009). Guía metodológica: diseño de indicadores compuestos de desarrollo sostenible.

de la Torre, R., y Gutiérrez, C. (2011). La neomexicanidad y los circuitos new age.i Un hibridismo sin fronteras o múltiples estrategias de sintesis espiritual?. Archives de sciences sociales des religions, (153), 183-206.

York, M (2004). Historical Dictionary of New Age Movements. The Scarecrow Press, Inc. Lanham, Maryland, and Oxford. 